\begin{abstract}
We explore the effects of taxes and subsidies on job creation, job destruction, employment, and wages in the Mortensen-Pissarides version of the search and matching equilibrium framework. Qualitative analytical results show that wage and employment subsidies increase employment, especially of low skill workers, and also increase wages. A job creation or hiring subsidy reduces unemployment duration but increases incidence with an ambiguous effect on overall employment. A firing tax has the reverse effects but the same indeterminacy. In the special case of a competitive search equilibrium, the one in which search externalities are internalized, there is a first best configuration: no tax on the wage, an employment subsidy that offsets the distortions on the job destruction margin induced by unemployment compensation and employment protection policy, and a hiring subsidy equal to the implicit tax on severance imposed by any form of employment protection, with the costs of these and other policies financed by a non-distortionary consumption tax. Computational experiments confirm this ideal also determines the direction in which marginal improvements can be made both in terms of efficiency and in terms of improving low skill worker employment and wage outcomes.
\end{abstract}

This paper was produced as part of the Centre's Technology and Growth Programme.

\title{
Acknowledgements
}

Dale T. Mortensen is Professor of Economics at Northwestern University, Chicago, USA. Christopher A. Pissarides is Professor of Economics at the London School of Economics and a programme head at the Centre for Economic Performance, London School of Economics.

Published by

Centre for Economic Performance

London School of Economics and Political Science

Houghton Street

London WC2A $2 \mathrm{AE}$

(C) D. T. Mortensen and C. A. Pissarides, submitted 2001

ISBN 07530

Individual copy price: $£ 5$ 


\section{Taxes, Subsidies and Equilibrium Labor Market Outcomes}

\section{Dale T. Mortensen and Christopher A. Pissarides}

1. Introduction

2. The Framework 2

2.1 Basic concepts 2

2.2 Job creation and job destruction 5

$\begin{array}{lll}2.3 & \text { Wage determination }\end{array}$

3. The Solution 12

$\begin{array}{lll}3.1 & \text { Market equilibrium } & 12\end{array}$

$\begin{array}{lll}3.2 & \text { Comparative static results } & 14\end{array}$

4. Computation Experiments 16

4.1 Functional forms and baseline parameters 16

$\begin{array}{lll}4.2 \text { Outcomes } & 18\end{array}$

4.3 Marginal effects of an employment subsidy 20

4.4 Marginal effects of a hiring subsidy 22

4.5 A self financing employment subsidy and wage tax 25

5. Conclusions and a Future Research Agenda 27

References $\quad 29$

$\begin{array}{ll}\text { Figure } & 32\end{array}$

The Centre for Economic Performance is financed by the Economic and Social Research Council. 


\section{Taxes, Subsidies and Equilibrium Labor Market Outcomes}

\section{Dale T. Mortensen and Christopher A. Pissarides}

1. Introduction

2. The Framework 2

2.1 Basic concepts 2

2.2 Job creation and job destruction 5

$\begin{array}{lll}2.3 & \text { Wage determination } & 9\end{array}$

3. The Solution 12

$\begin{array}{lll}3.1 & \text { Market equilibrium } & 12\end{array}$

$\begin{array}{lll}3.2 & \text { Comparative static results } & 14\end{array}$

4. Computation Experiments 16

4.1 Functional forms and baseline parameters 16

$\begin{array}{lll}4.2 \text { Outcomes } & 18\end{array}$

4.3 Marginal effects of an employment subsidy 20

4.4 Marginal effects of a hiring subsidy 22

4.5 A self financing employment subsidy and wage tax 25

5. Conclusions and a Future Research Agenda 27

$\begin{array}{ll}\text { References } & 29\end{array}$

$\begin{array}{ll}\text { Figure } & 32\end{array}$

The Centre for Economic Performance is financed by the Economic and Social Research Council 


\title{
Taxes, Subsidies and Equilibrium Labor Market Outcomes
}

\section{Dale T. Mortensen and Christopher A. Pissarides}

\author{
September 2001
}

1 Introduction

Our purpose is to consider various tax and subsidy effects on wages and unemployment within the search and matching labor market framework. This structure is the basis 
for the "flows" approach to aggregate labor market analysis. In Mortensen's and Pissarides's (1994) version, an existing employment relationship commands quasi-rent as a consequence of search and recruiting investment, hiring and firing costs, and other forms of match-specific human capital formation. The quasi-rents that accrue to any specific employer and worker pair are allocated between the parties by a wage contract. Given a particular wage determination rule, employers provide jobs and recruit workers while workers search for employment. At the same time, an existing employer-worker match ends when sufficiently bad news arrives about their expected future productivity. These job creation and job destruction decisions generate worker flows into and out of employment which depend on the current value of the employed stock. When the two flows differ, employment dynamics are set in motion which, under a reasonable set of conditions, lead to a unique steady-state employment level.

The search and matching approach owes its origins to the pioneering works of Stigler (1961), Phelps (1968) and Friedman (1968) and was already at an advanced state when the Phelps et al. (1970) volume was published. The equilibrium analysis of the current vintage of models, however, did not start until the early 1980s, when models by Diamond (1982a, 1982b), Mortensen (1982) and Pissarides (1985, 1986) explored the properties of two-sided search and characterized the nature and welfare properties of market equilibrium. A key ingredient of the new approach was the use of the solution to the Nash bargaining game to determine wages. The Nash solution is appropriate in this context because of the assumptions of two-sided search and the symmetry that they introduce to the game. It is also flexible enough to enable the study of market equilibrium under a variety of assumptions about parameters, including policy ones.

The policy parameters studied in this paper are a job creation subsidy, an implicit firing tax and a linear wage tax and employment subsidy imposed on continuing jobworker matches. We investigate the effects of each on job creation, job destruction, employment and wages. Because analytical results are often ambiguous, we conduct computational experiments that illuminate the model's implications.

\section{The Framework}

\subsection{Basic concepts}

The Mortensen-Pissarides model is founded on two constructs, a matching function that characterizes the search and recruiting process by which new job-worker matches are created and an idiosyncratic productivity shock that captures the reason for resource reallocation across alternative activities. Given these concepts, decisions about the cre- 
ation of new jobs, about recruiting and search effort, and about the conditions that induce job-worker separations can be formalized.

Job and worker matching is viewed as a production process. The flow of new matches that form is the output of the process and the search and recruiting efforts of workers and employers are the inputs. The matching function gives the aggregate relationship between matching output and the inputs. Under the simplifying assumptions that all employers with a vacancy recruit with equal intensity and that unemployed workers search, also at a given intensity, aggregate matching inputs can be represented simply by the numbers of job vacancies $v$ and the number of unemployed workers $u$.

Let the function $m(v, u)$ represent the matching rate associated with every possible vacancy and unemployment pair. As in production theory, it is reasonable to suppose that this function is increasing in both arguments but exhibits decreasing marginal products to each input. Constant returns in the sense that

$$
m(v, u)=m\left(1, \frac{u}{v}\right) v \equiv q(\theta) v \text { where } \theta=v / u,
$$

is a convenient additional assumption, one that is consistent with available evidence. ${ }^{1}$ The ratio of vacancies to unemployment $\theta$, market tightness, is an endogenous variable to be determined.

On average, a vacant job is taken by a worker at the rate $q(\theta)$ and workers find jobs at rate $\theta q(\theta)$. By the assumption of a concave and linear homogenous matching function, $q(\theta)$ is decreasing and $\theta q(\theta)$ increasing in $\theta . \theta q(\theta)$ is the unemployment duration hazard. The duration of unemployment spells is a random exponential variable with expectation equal to the inverse of the hazard, $1 / \theta q(\theta)$, a decreasing function of market tightness. Analogously, $q(\theta)$ is the vacancy duration hazard and its inverse, $1 / q(\theta)$, is the mean duration of vacancies.

An important source of job-worker separations is job destruction attributable to an idiosyncratic shock to match productivity. Empirically this is the main reason for job destruction (See Davis, Haltiwanger and Schuh (1996)). Initial decisions regarding location, technology, and/or product line choices embodied in a particular match are irreversible in the sense that subsequent innovations and taste changes, not known with certainty at the time of match formation, shock the market value of the product or service output. For example, the initial decision might involve the choice of locating a productive activity on one of many "islands". In future, island-specific conditions that affect total match productivity, say the weather, may change. If the news about future profitability implicit in the shock is bad enough, then continuation of the activity on

\footnotetext{
${ }^{1}$ See the survey by Petrongolo and Pissarides (2001).
} 
that particular island is no longer profitable. In this case, the job is destroyed and the match dissolves.

To model this idea, we assume that the output of each job is the product of two components, $p$, which is common to all jobs in a particular skill group, and $x$, which is idiosyncratic. The idiosyncratic component $x$, which takes values on the unit interval, arrives from time to time at the Poisson rate $\lambda$ and is distributed according to the c.d.f. $F(x)$ given an arrival. Note that these assumptions satisfy the empirical properties of idiosyncratic job destruction, i.e. the shocks have persistence and they appear to hit the job independently of the aggregate state or the skill of the worker (here represented by $p$ ). Furthermore, the sequence of shocks are iid.

The parameter $p$ represents the common productivity of a particular skill group. A key assumption is market segmentation, i.e., skill groups are not linked though migration, rivalry in the job search process, or common wage-setting institutions. In other words, each skill group participates in a separate labor market with its own matching function, tax and subsidy structure, and employment-wage equilibrium. Under this strong assumption, we can derive the equilibrium of one skill group without reference to others. $^{2}$ It will become obvious during the description of equilibrium why different skill groups experience different equilibrium employment-wage configurations.

Under our assumptions about the information structure and the behavior of firms and workers after the formation of a match, an existing match is destroyed if the idiosyncratic productivity shock falls below some reservation threshold, an endogenous variable denoted by $R$. Unemployment incidence is defined as the average rate of transition from employment to unemployment, $\lambda F(R)$, and increases with the reservation threshold.

Entrepreneurs are unconstrained with respect to initial location, technology and product choice and also have the same information about market conditions. Under the assumption that they know the product or service that commands the highest expected future profit, all will create jobs at the highest idiosyncratic productivity $x=1$. Given this property of the model and the assumption that future match product evolves according to a Markov process with persistence, the jobs that are still at initial productivity are the most productive for a given skill group. Note, however, this does not imply that new jobs have greater expected duration, which would violate the empirical facts. All jobs in our model, regardless of productivity, have the same expected duration, equal to the inverse of the job destruction rate, $1 / \lambda F(R)$, given the assumption that the sequence of shocks is iid.

\footnotetext{
${ }^{2}$ Implicit in the statement is the additional assumption that the labor services of members of two different skill groups are not substitutes for one another. The consequences of relaxing this assumption are discussed in the final section of the paper.
} 
As all workers are assumed to participate, the unemployed fraction of each skill group evolves over time in response to the difference between the flow of workers who transit from employment to unemployment and the flow that transits in the opposite direction, i.e.,

$$
\dot{u}=\lambda F(R)(1-u)-\theta q(\theta) u
$$

where $1-u$ represents both employment and the employment rate in each skill group. The steady state equilibrium unemployment rate is

$$
u=\frac{\lambda F(R)}{\lambda F(R)+\theta q(\theta)} .
$$

As individual unemployment histories are described by a simple two-state Markov chain, the steady-state unemployment rate is also the fraction of time over the long run that the representative participant spends unemployed. It decreases with market tightness and increases with the reservation product, because the unemployment hazard $\theta q(\theta)$ and the employment hazard $\lambda F(R)$ are both increasing functions.

\subsection{Job creation and job destruction}

The sequence of events that lead to job creation and job destruction can be summarized as follows. A firm with a profit opportunity opens a job vacancy for a worker with skill indexed by $p$ at a flow cost of recruiting equal to $c p$. Applications from workers begin arriving at hazard rate $q(\theta(p))$, and one is received on average $1 / q(\theta(p))$ periods after the posting of the vacancy. When they meet, worker and employer bargain. After the initial wage $w_{0}(p)$ is agreed to, job creation takes place: the firm pays set-up cost $p C$, which includes the cost of hiring, training and other forms of match specific investment. Production then takes place, until a productivity shock arrives. Wage renegotiation occurs with wage outcome $w(x, p)$ prevailing on any continuing job, one that generally reflects the new information $x$. However, if $x$ falls below some reservation level $R(p)$, job destruction takes place: the firm pays firing cost $p T$ and exits the market and the worker enters unemployment. Here we have in mind an implicit firing tax, one imposed by employment protection regulations that restrict 'employment at will', not a severance transfer from firm to worker. ${ }^{3}$

Note that the vacancy-posting, job-creation and job-termination costs are assumed to be proportional to the worker skill parameter. This reflects the reasonable assumption

\footnotetext{
${ }^{3}$ In the case of the principal wage contract assumed, such a transfer has no allocation effect for reasons pointed out by Lazear (1990) and Burda (1992).
} 
that it is more expensive to the firm to maintain a skilled job vacant than a less skilled one and more expensive to train a more skilled worker to the special requirements of the job (because the job is more demanding). The termination cost is an implicit tax, and again the reasonable assumption is that it is more costly to get rid of a more skilled worker than of a less skilled one. Of course, the assumption of proportionality is a simplification that may not hold precisely in all situations. For example, termination costs may increase with the wage rather than with productivity. Any other assumption, however, would complicate the model considerably and the simulations show that results with the proportionality assumption are reasonable.

The following policy parameters are studied. First, a job creation or hiring subsidy, denoted as $p H$ and defined as a payment made to the employer when a worker is hired. Second, a linear labor tax-subsidy schedule, $a+t w$, imposed on employers. If $t=0$, the schedule corresponds to a pure employment subsidy when $a<0$ and a lump-sum employment tax if $a>0$. If $t>0$, the schedule corresponds to a progressive tax if $a<0$ and a regressive one if $a>0$. For $t<\tau$ where $\tau$ represents the underlying payroll tax, $\tau-t$ is a wage subsidy of the kind advocated by Phelps (1997). Third, as already indicated, we also consider an explicit job destruction tax, $p T$ as a policy instrument. Finally, we allow for an unemployment compensation payment equal to some fraction of the average wage for each skill group, $\rho \bar{w}(p)$, where the fraction $\rho$ is the replacement ratio.

The policy-free equilibrium is one characterized by $H=T=a=t=\rho=0$. Our assumptions about the policy parameters are that in addition to the firing tax, the hiring subsidy is also proportional to productivity, but the rates $a, t$ and $\rho$ are independent of productivity. $H$ is modelled as a hiring subsidy that is proportional to productivity for convenience. Given the private cost of hiring, $C$, which is proportional to productivity, $p(C-H)$ is the net private job creation cost for each skill group $p$. That $t$ and $\rho$ are independent of productivity needs no explanation, because they are both rates that apply to equilibrium wage outcomes which depend on productivity. By making them constant we restrict ourselves to linear schedules. $a$ is treated as a flat (lump sum) employment subsidy for keeping a worker employed, regardless of skill.

In addition to unemployment compensation, $\rho \bar{w}(p)$, each unemployed worker enjoys imputed income during unemployment $b>0$. Crucially, this 'income' is independent of skill. It is the imputed value of leisure (home production) to the worker although it may include other incomes that must be given up when the worker moves from nonemployment to employment. The critical assumption is that the value of home production to the worker is independent of market skill. This assumption is the reason that the employment-wage configurations that we derive depend on skill: more skilled workers enjoy on average lower relative returns from home production, $b / p$, and so they should be 
expected, on average, to have higher employment rates. In a general utility-maximizing framework and in a (very) long-run equilibrium, $b$ might depend on market productivity through wealth accumulation, a point emphasized by Phelps (see, for example the Phelps and Hoon paper in this volume). We ignore such a dependence here.

A formal equilibrium model of unemployment requires specification of a production technology, preferences, expectations, and a wage determination mechanism. Match output is proportional to employment where the factor of proportionality, $p x$, varies with the worker's skill level $p$ and the job's idiosyncratic shock $x$. Both workers and employers maximize human wealth, defined as the expected present value of future net income streams conditional on current information. Forward-looking rational expectations are imposed. Wages are determined by a bilateral bargaining after the firm and worker meet.

Given these assumptions, equilibrium market tightness, the ratio of vacancies to unemployment $\theta(p)$, satisfies the following job creation condition: the expected present value of the future return to hiring a worker equals the expected cost. Of course, a hiring decision, implicit in the act of posting a job vacancy, is taken by an employer. The equilibrium reservation product reflects the decisions of both parties to continue an existing employment relationship. Individual rationality implies that separation occurs when the forward looking capital value of continuing to either party is less than the capital value of separation. For joint rationality, the sum of the values of continuing the match must be less than the sum of the values of separating, otherwise a redistribution of the pair's future incomes can make both better off. Whether these job destruction conditions also satisfy the requirements of joint optimality depends on the wage mechanism assumed. For a given wage determination mechanism, a search equilibrium is a pair $(R(p), \theta(p))$ for each skill level $p$ that simultaneously solves these job creation and job destruction conditions. Given our assumptions of market segmentation along skill lines, we can ignore from now on in the notation the functional dependence of all equilibrium mappings on $p$.

A wage contract, formally a pair $\left(w_{0}, w(x)\right)$, is composed of a starting wage $w_{0} \in \Re$ and a continuing wage function $w: X \rightarrow \Re$ that obtains after any future shock to match specific productivity. Implicit in this specification is the idea that a worker and an employer negotiate an initial wage when they meet and then subsequently renegotiate in response to new information about the future value of their match. ${ }^{4}$

\footnotetext{
${ }^{4}$ Note that contracts of this form are instantly "renegotiated" on the arrival of a new idiosyncratic shock. MaCleod and Malcomson (1993) persuasively argue that the initial wage need not be renegotiated until an event occurs that would otherwise yield an inefficient separation. Contracts of this form may well generate more realistic wage dynamics but job creation and job destruction decisions are the same under theirs and our specification, provided the initial wage does not violate any non-negativity or
} 
A continuing match has specific productivity $x$ and the worker is paid a wage $w(x)$. Given that the match ends in the future if a new match specific shock $z$ arrives which is less than some reservation threshold $R$, its capital value to an employer, $J(x)$, solves the following asset pricing equation for each $p$ :

$$
r J(x)=p x-a-(1+t) w(x)+\lambda \int_{R}^{1}[J(z)-J(x)] d F(z)+\lambda F(R)[V-p T-J(x)]
$$

where $r$ represents the risk free interest rate, $V$ is the value of a vacancy, and $a, t$ and $T$ are policy parameters. An analogous relationship implicitly defines the asset value of the same match to the worker involved, $W(x)$. Namely,

$$
r W(x)=w(x)+\lambda \int_{R}^{1}[W(z)-W(x)] d F(z)+\lambda F(R)[U-W(x)]
$$

where $U$ is the capital value of unemployment.

Given a match product shock $z$, the employer prefers separation if and only if its value as a vacancy $V$ exceeds the value of continuation $J(z)$ plus the firing cost $p T$. Similarly, the worker will opt for unemployment if and only if its value, $U$, exceeds $W(z)$. Given that under our wage rule both $J(z)$ and $W(z)$ are increasing (see below), separation occurs when a new value of the shock arrives that falls below the reservation threshold

$$
R=\max \left\{R_{e}, R_{w}\right\}
$$

where $J\left(R_{e}\right)=V-p T$ and $W\left(R_{w}\right)=U$. Because in the bilateral bargain wealth is transferable between worker and employer, the separation rule should be jointly optimal in the sense that it maximizes their total wealth. The necessary and sufficient condition for joint optimization is that $R=R_{e}=R_{w}$ where $J(R)+W(R)=V-p T+U$, a condition that holds only for an appropriately designed wage contract.

Although the idiosyncratic component of a new job match is $x=1$, the expected profit from a new match may be different from $J(1)$, as defined in (4), because of the existence of the job creation cost, $p C$, and the policy parameters $p H$ and $p T$. We therefore introduce the notation $J_{0}$ for the expected profit of a new match to the employer and write the asset pricing equation for the present value of an unfilled vacancy, $V$, as

$$
r V=q(\theta)\left[J_{0}-V-p(C-H)\right]-p c
$$

other (e.g. minimum wage) constraints. Hence, for the purpose at hand, there is no relevant difference. However, their observation does suggest a possible explanation within our framework for the observed "stickiness" of wage rates, which, nonetheless, is not a cause of "under-employment" equilibria. 
where $p c$ is the recruiting cost flow per vacancy held, $p C$ is a fixed cost of hiring and training a new worker plus any other match specific investment required and $p H$ is the hiring subsidy given by the government. Similarly, the value of unemployment solves

$$
r U=b+\rho \bar{w}+\theta q(\theta)\left[W_{0}-U\right]
$$

where $b$ is the flow of imputed income during unemployment and $\rho \bar{w}$ is the unemployment compensation: $\rho$ is a policy parameter and $\bar{w}$ is the mean wage for the skill group. Note that the opportunity cost of employment is invariant with respect to the worker's skill as reflected in the parameter $p$ by assumption.

Given an initial wage equal to $w_{0}$, the asset pricing relation implies that the initial value of a match to employer and worker respectively satisfy

$$
r J_{0}=p-a-(1+t) w_{0}+\lambda \int_{R}^{1}\left(J(z)-J_{0}\right) d F(z)+\lambda F(R)\left[V-p T-J_{0}\right] .
$$

and

$$
r W_{0}=w_{0}+\lambda \int_{R}^{1}\left(W(z)-W_{0}\right) d F(z)+\lambda F(R)\left[U-W_{0}\right]
$$

where $(J(x), W(x))$ represents the values of match continuation defined above.

Free entry requires that new vacancies are created until the capital value of holding one is driven to zero, i.e.,

$$
V=0 \Leftrightarrow \frac{p c}{q(\theta)}+p(C-H)=J_{0}
$$

As the expected number of periods required to fill a vacancy is $1 / q(\theta)$, the condition equates the cost of recruiting and hiring a worker to anticipated discounted future profit stream. The fact that vacancy duration is increasing in market tightness guarantees that free entry will act to equate the two.

\subsection{Wage determination}

The generalized axiomatic Nash bilateral bargaining outcome with "threat point" equal to the option of looking for an alternative match partner is the baseline wage specification assumption found in the literature on search equilibrium. ${ }^{5}$ Given that the existence of

\footnotetext{
${ }^{5}$ See Diamond (1981,1982b), Mortensen (1978, 1982), and Pissarides (1986,1990).
} 
market friction creates quasi-rents for any matched pair, bilateral bargaining after worker and employer meet is the natural starting point for an analysis. ${ }^{6}$

Given the notation introduced above, the starting wage determined by the generalized Nash bargain over the future joint income stream foreseen by worker and employer supports the outcome

$$
w_{0}=\arg \max \left\{\left[W_{0}-U\right]^{\beta}\left(S_{0}-\left(W_{0}-U\right)\right)^{1-\beta}\right\}
$$

subject to the following definition of initial match surplus

$$
S_{0} \equiv J_{0}-p(C-H)-V+W_{0}-U \text {. }
$$

In the language of axiomatic bargaining theory the parameter $\beta$ represents the worker's relative "bargaining power." Analogously, the continuing wage contract supports the outcome

$$
w(x)=\arg \max \left\{[W(x)-U]^{\beta}(S(x)-(W(x)-U))^{1-\beta}\right\}
$$

where continuing match surplus is defined by

$$
S(x) \equiv J(x)-V+p T+W(x)-U .
$$

The difference between the initial wage bargain and subsequent renegotiation arises for two reasons. First, hiring costs are "sunk" in the latter case but "on-the-table" in the former. Second, termination costs are not incurred if no match is formed initially but must be paid if an existing match is destroyed.

The solution to these two different optimization problems satisfy the following first order conditions

$$
\beta\left(J_{0}-V-p(C-H)\right)=(1-\beta)(1+t)\left(W_{0}-U\right)
$$

and

$$
\beta(J(x)-V+p T)=(1-\beta)(1+t)(W(x)-U)
$$

where $\beta$, the worker's "bargaining power" is the resulting worker's share of match surplus in the absence of taxes. But when there is marginal taxation the worker's share falls,

\footnotetext{
${ }^{6}$ See Binmore, Rubinstein, and Wolinsky (1986), Rubinstein and Wolinsky (1985) and Wolinsky (1987) for applications of Rubinstein's strategic model model in the search equilibrium framework. Although the precise form of the wage contract can differ under alternative specifications of the stategic bargaining game, all outcomes that are efficient from the perspective of any employer-worker pair yield the same job destruction decisions. Job creation decisions, however, may differ, because they depend on the share of the surplus going to one side only.
} 
because firm and worker realize that they can pay less tax (a net loss to the pair) by reducing the negotiated wage. As an immediate consequence of (15), it follows that the reservation threshold $R$, defined by equation (6) is jointly rational, i.e., it solves

$$
S(R)=J(R)-V+p T+W(R)-U=0 .
$$

In order to solve for the equilibrium $(\theta, R)$ pair, we first use the asset value equations and the sharing rules to solve for initial wages and wages in continuing jobs:

$$
w_{0}=(1-\beta)(b+\rho \bar{w})+\frac{\beta}{1+t}[p-a+p c \theta-(r+\lambda) p(C-H)-\lambda p T]
$$

and

$$
w(x)=(1-\beta)(b+\rho \bar{w})+\frac{\beta}{1+t}[p x-a+p c \theta+r p T]
$$

The dependence of these wages on the policy parameters needs some explanation. Both wage functions depend on $a$ and $t$, because all jobs pay these taxes. The employment tax a reduces job surplus directly, so it is simply deducted from the match product before the latter is shared. The marginal tax $t$ influences the share going to each party in the bargaining outcome. Specifically, because $t$ affects the marginal rate at which the surplus can be traded between worker and employer, the tax rate influences the net share of match product obtained by the worker. The similarity between the two wage functions, however, stops there. The net job creation cost $p(C-H)$ reduces the initial wage, because the cost is conditional on an agreement to form the match and hence must be shared. But once the job is formed, the creation cost is sunk and as such does not influence wages in continuing jobs. The firing cost $p T$ reduces expected match surplus at the creation date and so reduces the initial wage for that reason. However, once the job is formed, the firing tax is an employer liability if the job is destroyed. This fact strengthens the worker's hand in the wage bargain and so pushes the negotiated wage up for continuing workers. Equation (17) reflects the fact that the second influence dominates the first so the wage in continuing matches goes up by the introduction of the firing cost. ${ }^{7}$

\footnotetext{
${ }^{7}$ From an accounting perspective, the worker pays her share of expected amortized cost of termination at the first shock, $\beta \lambda p T /(1+t)$, in the form of a lower wage flow over the period prior to the first shock arrival. Subsequently, she earns the market return on the prior 'forced saving', equal to $\beta r p T /(1+t)$, as long as the match continues.
} 


\section{The Solution}

\subsection{Market equilibrium}

It remains to substitute the wage equations into the asset value equations and the job creation and job destruction conditions, in order to derive overall market equilibrium. Substitution into the job value conditions yields

$$
\begin{aligned}
(r+\lambda) J_{0}= & (1-\beta)[p-(1+t)(b+\rho \bar{w})-a]-\beta p c \theta+\beta(r+\lambda) p(C-H) \\
& +\beta \lambda p T+\lambda \int_{R}^{1} J(z) d F(z)-\lambda F(R) p T
\end{aligned}
$$

and

$$
\begin{aligned}
(r+\lambda) J(x)= & (1-\beta)[p x-(1+t)(b+\rho \bar{w})-a]-\beta p c \theta-\beta r p T \\
& +\lambda \int_{R}^{1} J(z) d F(z)-\lambda F(R) p T
\end{aligned}
$$

Jobs are destroyed when

$$
J(R)+p T=0 .
$$

Equations (18), (19) and (20) imply the job creation condition

$$
J_{0}=(1-\beta) p\left(\frac{1-R}{r+\lambda}-T\right)+\beta p(C-H),
$$

and the job destruction condition

$$
R+\frac{\lambda}{r+\lambda} \int_{R}^{1}(z-R) d F(z)=\frac{a+(1+t)(b+\rho \bar{w})}{p}+\frac{\beta}{1-\beta} c \theta-r T .
$$

Finally, from (11) and (21) $\theta$ is the solution to

$$
(1-\beta)\left(\frac{1-R}{r+\lambda}-T-C+H\right)=\frac{c}{q(\theta)} .
$$

In (22), the reservation product, $R$, plus the option value of continuing the match attributable to the possibility that match product will increase in the future, the left side, equals the match continuation opportunity cost flow, the right side of the equation. Higher market tightness increases the reservation productivity because the worker's outside options improve with $\theta$. For given market tightness, both the firing tax and the 
employment and wage tax increase the reservation productivity and consequently reduce the surplus value of a continuing match.

In (23), the left side is the firm's share of the expected net surplus attributable to a newly created job. The right side is the expected recruiting cost. Higher reservation productivity implies a shorter expected life of a new job and so desired job creation and with it market tightness fall. For given reservation productivity, higher job creation or job destruction costs reduce desired job creation as well.

Now, (22) and (23) can be represented by two curves in $R \times \theta$ space, the former sloping up and the latter sloping down, for reasons just explained. This is shown in Figure 1. Hence there is an equilibrium pair $\left(R^{*}, \theta^{*}\right)$ for each $p$ which is unique. Of course, the ratio of vacancies to unemployment must be strictly positive $(\theta>0)$ in any meaningful equilibrium. Indeed, the following conditions are necessary but not generally sufficient:

$$
\begin{aligned}
1 & >(r+\lambda)(C-H+T) \\
p(1+r T) & >a+(1+t)(b+\rho \bar{w}) .
\end{aligned}
$$

Satisfaction of these two conditions restricts the magnitude of hiring and firing costs and the income while unemployed relative to the level of average productivity.

Outcome variables of interest include the unemployment rate, the average wage and aggregate income per participant. Given the equilibrium pair $\left(R^{*}, \theta^{*}\right)$, the associated unemployment rate $u$ is determined by the Beveridge equation (3).

For given $\theta$, the wage equations (16) and (17) define the equilibrium wage schedules in new and continuing jobs, respectively. As the steady state fraction of newly created jobs is $F(R)$ while the fraction of continuing jobs with idiosyncratic productivity $x$ or less is $F(x)-F(R)$, the average wage is simply

$$
\bar{w}=w_{0} F(R)+\int_{R}^{1} w(x) d F(x) .
$$

After rearranging terms and substituting from (16) and (17) into (25) one obtains,

$$
\begin{aligned}
\bar{w} & =w_{0} F(R)+(1-F(R)) w(R)+\frac{\beta p}{1+t} \int_{R}^{1}(x-R) d F(x) \\
& =(1-\beta)(b+\rho \bar{w})+\frac{\beta}{1+t}\left[\begin{array}{c}
p((1-R)-(r+\lambda)(C-H+T)) F(R) \\
+p(R+r T)-a+p c \theta+\int_{R}^{1}(x-R) d F(x)
\end{array}\right]
\end{aligned}
$$


Therefore, the equilibrium conditions (22) and (23) imply

$$
\bar{w}=b+\rho \bar{w}+\frac{p \beta}{(1+t)(1-\beta)}\left[\begin{array}{c}
\frac{c}{q(\theta)}((r+\lambda) F(R)+\theta q(\theta)) \\
+\frac{r(1-\beta)}{r+\lambda} \int_{R}^{1}(x-R) d F(x)
\end{array}\right] .
$$

Finally, aggregate income per participant, the sum of market output net of recruiting and job creation costs plus unemployment output, can be written as

$$
\begin{aligned}
y & =p\left[F(R)+\int_{R}^{1} x d F(x)\right](1-u)+b u-p c v-p C m(v, u) \\
& =p\left[F(R)+\int_{R}^{1} x d F(x)\right](1-u)+(b-p c \theta-p C \theta q(\theta)) u .
\end{aligned}
$$

Given unemployment, income increases with the reservation product and decreases with market tightness

The differences between the equilibrium employment-wage combinations of skilled and unskilled workers can be seen with the help of figure 1. Inspection of the equations for the two curves, (22) and (23) shows that differences in the skill parameter $p$ are reflected in differences in the location of the job destruction curve (22). Higher $p$ implies that the job destruction curve lies at a lower position than it does with lower $p$. So skilled workers, who have the higher $p$, experience equilibrium outcomes with lower $R$ and higher $\theta$, i.e., for given unemployment, lower job destruction rate and higher job creation rate. The Beveridge curve then implies that the unemployment rate for skilled workers is lower in equilibrium. The wage equations also imply that the wage rate for skilled workers is higher, partly because of their higher productivity but also because of the more tight skilled markets.

Equation (22) makes clear why there are differences between the equilibrium combinations of the two skill groups. In the absence of policy, both skilled and unskilled workers have the same imputed value of leisure but different market returns. So the more skilled workers gain more from employment, relative to their home returns, giving rise to their higher employment rates. With policy, the gain is affected by the employment subsidy and the tax rate (but not by the unemployment benefit, which is proportional to wages), both of which are independent of skill.

\subsection{Comparative Static Results}

The tax parameters $a$ and $t$, as well as the supply price of labor, $b$, and unemployment compensation, $\rho \bar{w}$, all shift the job destruction curve up but have no direct effect on the 
job creation curve. As a consequence, the equilibrium value of the reservation threshold increases and the equilibrium value of market tightness falls. Hence, steady state unemployment increases because both unemployment duration and incidence increase in response. Wages, however, increase in $b$ and $\rho \bar{w}$ but fall in the tax instruments. It follows that if we interpret a fall in $a$ financed by a lump-sum consumption tax as an employment subsidy, both employment and wages rise in response. A fall in $t$ has similar effects.

Now, because the effect of both $a$ and $t$ on employment is inversely proportional to $p$, the general productivity of a skill group, the effect of taxing or subsidizing employment by a given amount is larger for low-skill groups. Of course, if employment subsidies were proportional to the average skill level in each case, the differential effect of employment subsidies would disappear. But then the authorities would be spending a lot more on subsidizing skilled employment than unskilled. Also, the differential effects of the tax rate would remain. The reason for the differential effects of tax rates, if we ignore employment subsidies, is that leisure activities are not taxed. Therefore, the effect of the tax is the same as the effect of a subsidy on home activities. Because low-skill groups have higher imputed income from home production, a given percentage subsidy has bigger impact on behavior. If home production were taxed, or if it depended on wealth that was taxed, directly or indirectly, the effect would disappear in the long run.

With flat-rate subsidies and untaxed home production, it would be beneficial in terms of overall employment to tax high-skill groups and use the revenue to subsidize low-skill groups. The employment benefit at the lower end of the skill distribution outweighs the loss at the top end. In the wage equations, the effect of different $a$ on wages is the same across all occupational groups. But the effect of different $t$ is higher for higher-skill groups than for lower ones. So a uniform tax should reduce wage inequality. Of course, taxing high-skill groups and subsidizing low-skill groups should also reduce inequality.

An increase in the hiring subsidy $H$ inflates demand and consequently shifts the job creation curve up in Figure 1. Both the equilibrium reservation threshold and market tightness rise in response, inducing respectively a decrease in unemployment duration and an increase in unemployment incidence. Hence, the net effect on steady-state unemployment is qualitatively indeterminate. Initial wages also increase with $H$ but wages in continuing jobs are not directly affected, except to the extent that the rise in tightness increases them. It follows that if the government subsidizes job creation, it reduces unemployment duration but increases unemployment incidence. It also increases wages, especially those of newly hired workers.

Changes in the firing tax $T$ have more complicated effects on unemployment duration and incidence. An increase in $T$ shifts both the job destruction curve and the job creation curve down. Although the effect on market tightness appears ambiguous, a formal 
differentiation of the equilibrium conditions yields a negative net effect on both $R$ and $\theta$. Still, because of the negative effect of firing costs on job creation, the qualitative effect on steady state unemployment is indeterminate. Initial wages fall with $T$ but wages in continuing jobs rise, thus making the wage-tenure profile steeper.

\section{Computation Experiments}

In this section, we present computed solutions to the model that provide some numerical feel for its policy implications. Parsimonious functional forms are assumed. Some of the parameters are set at reasonable values while others are chosen to match unemployment spell durations and incidences typically experienced by workers in the US economy. Two different initial labor policy configurations are considered, one in which the unemployment benefit replacement ratio is moderate and unemployment protection legislation is weak, as in the US, and another in which both the level of unemployment compensation and the extent of employment protection are relatively high, as in Europe. The simulated numerical effects of employment and hiring subsidies are reported for each case for both 'high' and 'low' skill workers.

\subsection{Functional forms and baseline parameters}

The matching function is log-linear. Formally,

$$
q(\theta)=\theta^{-\eta}
$$

where without loss of generality the scale parameter is normalized to one (this assumption simply determines the units in which $v$, and so $\theta$, are measured) and $\eta$ is the constant elasticity of the matching function with respect to unemployment. The distribution of the idiosyncratic shock to match productivity is uniform over the interval $[\gamma, 1]$, i.e.,

$$
F(x)=\frac{x-\gamma}{1-\gamma}
$$

The baseline parameter used for the two policy cases under study are presented in Table 1. The normalized skill parameter value $p=1$ is interpreted as the initial match product of a worker of average ability. The difference between the two policy scenarios involves the values of the policy parameters $\rho$ and $T$. In case 1 , the replacement ratio is set equal to 0.2 and there is no employment protection policy, a specification consistent with the OECD characterization of US policy (see OECD, 1994). 
The numerical analysis abstracts from the possible effects of search externalities by considering only the case of an efficient equilibrium solution to the model, that is obtained by imposing the condition $\beta=\eta$. As is well known, this condition internalizes the effects of the search externalities on the equilibrium outcome (Hosios, 1990, Pissarides, 1990). In the initial calibration exercise, the wage tax $t$ is set equal to a typical payroll tax rate of $\tau=0.2$. This payroll tax, used in virtually all countries to finance social security expenditures, is possibly a bit high in a US context and definitely too low for the typical European country.

After setting all the other parameter values as in Mortensen (1994), unemployment output $b$ and the lower shock bound $\gamma$ are chosen so that the steady state unemployment rate, $u$, equals 6.5 percent and the average duration of an unemployment spell, $1 / \theta q(\theta)$, is one quarter, values which reflect US experience in the past twenty years. In case 2 , the policy parameters are set to obtain the same steady state unemployment rate but an average unemployment duration twice as long, about six months. This case, one in which unemployment spells are longer but less frequent, reflects European experience (see OECD, 1994), at least until the recent run up in long term unemployment. These assumptions, the other parameter values, and the model imply a case 2 replacement ratio consistent with those observed in Europe, $\rho=0.34$, and an implicit firing cost, $T=0.78$, which is roughly equal to the average quarterly wage in the benchmark model.

Table 1: Baseline Parameter Values

\begin{tabular}{l|l|l}
\hline Parameter & Case 1: 'US Policy' & Case 2: 'EU Policy' \\
\hline Match product $p$ & 1 & 1 \\
Interest rate $r$ & 0.02 & 0.02 \\
Shock arrival rate $\lambda$ & 0.1 & 0.1 \\
Lower shock support $\gamma$ & 0.646 & 0.646 \\
Duration elasticity $\eta$ & 0.5 & 0.5 \\
Recruiting cost $c$ & 0.3 & 0.3 \\
Creation cost $C$ & 0.3 & 0.3 \\
Value of leisure $b$ & 0.349 & 0.349 \\
Payroll tax rate $\tau$ & 0.2 & 0.2 \\
Firing tax $T$ & 0 & 0.78 \\
UI replacement ratio $\rho$ & 0.2 & 0.35 \\
\hline
\end{tabular}




\subsection{Outcomes}

Outcome variables include the steady state unemployment rate, average wage, and aggregate income. After solving for the equilibrium $(R, \theta)$ pair, unemployment is computed using the Beveridge equation (3). Equations (26) and (27) are used to calculate the average wage and aggregate income per participant respectively.

In Tables 2 and 3, outcome variable values are reported for both policy scenarios and two levels of worker 'skill'. For each outcome variable, case, and work skill type, both the actual simulated value and the 'first best' value are reported along with an employment subsidy and hiring subsidy that will implement first best. First best is defined as the equilibrium where the effect of all policy instruments combined on the $(R, \theta)$ pair is zero. From $((22)$ and $(23)$, given that $\beta=\eta$, first best is a configuration of the policy instruments that satisfies

$$
a+(1+t)(b+\rho \bar{w})-r p T=b
$$

and

$$
H=T .
$$

In working out the simulated first best solution, we treat $T, \rho$ and $t$ as parameters and $H$ and $a$ as the 'unknowns' of the simultaneous solution of (30) and (31); i.e. we look for a hiring subsidy and an employment subsidy that will offset the effects of the tax, firing restrictions and unemployment benefit on the equilibrium outcome. 'High skill' workers are assigned a productivity parameter of $p=1.4$ while low skill are assigned $p=0.75$. Given the normalization $p=1$ for the productivity parameter of an average worker, these are the average calibrated values derived in Millard and Mortensen (1996) using 1990 aggregate US earnings data by educational attainment if one defines 'low skill' as those with a high school diploma or less and 'high skill' as those with more than a high school education. 
Table 2: Outcomes: High Skill $(p=1.4)$

\begin{tabular}{l|ll|ll}
\hline & \multicolumn{2}{|l|}{ Case 1} & $(\rho, T)=(.2,0)$ & \multicolumn{2}{l}{ Case $2(\rho, T)=(.34, .78)$} \\
& Actual & First Best & Actual & First Best \\
\hline Unemployment rate $u$ & 5.3 & 4.2 & 4.5 & 4.2 \\
Average wage $\bar{w}$ & 1.08 & 1.41 & 1.03 & 1.71 \\
Aggregate income $y$ & 1.25 & 1.26 & 1.25 & 1.26 \\
Replacement ratio $\rho$ & 0.2 & 0.2 & 0.34 & 0.34 \\
Firing cost $T$ & 0.0 & 0.0 & 0.78 & 0.78 \\
Wage tax $t$ & 0.2 & 0.2 & 0.2 & 0.2 \\
Employment subsidy $-a$ & 0.0 & 0.41 & 0.0 & 0.75 \\
Hiring subsidy $H$ & 0.0 & 0.0 & 0.0 & 0.78 \\
\hline
\end{tabular}

For high skill workers in the 'US' policy scenario, the first best unemployment rate is only 1 percentage point less than the actual in policy case 1 and 3/10th of a point in policy case 2 and there is little overall welfare loss attributable to passive labor market policies as measured by aggregate income per participant in either case. However, the average wage after first best is attained by subsidizing employment is much larger than the actual in both cases.

There are two interrelated reasons for such a large response in the wage to an employment subsidy. First, a higher subsidy has a direct positive effect on wages but also increases unemployment compensation given a fixed replacement ratio which in turn induces a second round increase in the wage. (See equations (16) and (17)). Second, the induced increase in unemployment compensation increases the distortion further which causes a need for a second round increase in the subsidy to achieve first best. As a consequence of these multiplier processes, the wage increases by almost the amount of the subsidy, 0.41 , in spite of the fact that the workers' share of the direct subsidy is only equal to $\beta=0.5$.

For 'low skill' workers the employment and efficiency gains are large. Even in the 'US' policy scenario, actual unemployment is twice first best and aggregate output per participant is almost $2 \%$ less than potential. In policy case 2 , characterized by high unemployment compensation and strict employment protection, the actual unemployment rate is three times first best and first best output is over $3 \%$ larger than actual. In both cases, the wage is again augmented by almost the size of the subsidy. 
Table 3: Outcomes: Low Skill $(p=0.75)$

\begin{tabular}{l|ll|ll}
\hline & \multicolumn{2}{|l|}{ Case 1} & $(\rho, T)=(.2,0)$ & \multicolumn{2}{l}{ Case $2(\rho, T)=(.34, .78)$} \\
& Actual & First Best & Actual & First Best \\
\hline Unemployment rate $u$ & 9.0 & 5.2 & 16.2 & 5.2 \\
Average wage $\bar{w}$ & 0.588 & 0.796 & 0.563 & 0.965 \\
Aggregate income $y$ & 0.679 & 0.684 & 0.651 & 0.684 \\
Replacement ratio $\rho$ & 0.2 & 0.2 & 0.34 & 0.34 \\
Firing cost $T$ & 0 & 0 & 0.78 & 0.78 \\
Wage tax $t$ & 0.2 & 0.2 & 0.2 & 0.2 \\
Employment subsidy $-a$ & 0 & 0.261 & 0 & 0.452 \\
Hiring Subsidy $H$ & 0 & 0 & 0 & 0.78 \\
\hline
\end{tabular}

\subsection{Marginal Effects of an Employment subsidy}

An employment subsidy is an employment-contingent flow paid throughout the duration of a job-worker match. This contrasts with a wage subsidy, which can be regarded as a reduction in the payroll tax. We report results with wage subsidies normalized by the average wage, i.e., if $a$ is the flat employment subsidy, we report results for a range of $s$ values, where $s$ is defined by

$$
s=-a / \bar{w} .
$$

The normalization in (32) helps in the comparison with a wage subsidy in the following sense. Define a wage subsidy by a reduction in the tax rate $t$. The cost to the government of this reduction is $t \bar{w}$, so a reduction of the tax by an amount $s$ is comparable to an employment subsidy of $s$ as defined in (32), in the sense that to finance either requires the same consumption tax. Now, from (22) and (23), if an employment subsidy $s$ were enacted, its effect on equilibrium would be a displacement of (22) by an amount $s \bar{w} / p$. If a wage subsidy of $s$ were offered, its effect would be a displacement of the same condition by an amount $s(b+\rho \bar{w}) / p$. Because a meaningful equilibrium requires that unemployment income be less than income from work, i.e. $b+\rho \bar{w}<\bar{w}$, the effect of an employment subsidy per dollar of consumption tax dominates that of a wage subsidy (holding $\rho \bar{w}$ constant). Thus, it is cheaper to use an employment subsidy to achieve whatever effect on the employment outcome is desired than to use a wage subsidy. But the effects of the two policies on wages are different, as the wage equations (16) and (17) make clear. A reduction of $t$ by an amount $s$ and a reduction of $a$ by an amount $s \bar{w}$ both increase wages at all productivity levels, but because mean wages have to be 
less than productivity in a meaningful equilibrium, a wage subsidy has bigger effect on wages than an employment subsidy of the same value.

In what follows we consider only the marginal effects of an employment subsidy $s$, as defined in (32). The values considered in the simulations range from 0 to $20 \%$ of the average wage. The upper bound is equal to the size of the underlying payroll tax assumed in the experiment and in all cases is less than the level required to attain first best (See Tables 2 and 3). In all likelihood, it also exceeds the magnitude of any politically feasible subsidy.

The computed numerical effects of the employment subsidy on the unemployment rate and the other two outcome variables, the average wage and aggregate income per participant, for both policy scenarios and skill levels are reported in Table 4. The subsidy is expressed as a percentage of the initial average wage and the wage and income effects are stated as percentage changes relative to their initial values to facilitate comparison.

Table 4 sends a clear message. Although an employment subsidy reduces unemployment in all cases, the effect is virtually non-existent for a worker of high-skill, $p=1.4$, under either policy scenarios. However, the low-skill unemployment rate falls substantially with the employment subsidy, although much more so under a 'European' policy regime, case 2, than under a 'US' policy regime, case 1. For a worker of high skill there is virtually no efficiency gain to be realized over the employment subsidy range under consideration, despite the unemployment fall, but the average worker's wage does increase, at the rate of 80 cents on a dollar of subsidy.

In the low-skill worker case, the allocation effects are dramatic, particularly under the case 2 policy scenario. Even when policy is of the 'US' variety, case 1, the unemployment rate falls from 9 to 6.7 percent as the subsidy increases from zero to $20 \%$ of wages. When employment protection policy restricts reallocation and unemployment compensation is high as in Europe, the model suggests that efficiency gains are substantial as well. For example, a $20 \%$ subsidy induces a $4 \%$ increase in income. Furthermore, unemployment falls from $16 \%$ to less than $8 \%$ and again wages increase with the subsidy at a rate of roughly 80 cents on the dollar in both cases. 
Table 4: Effects of an Employment Subsidy

\begin{tabular}{|c|c|c|c|c|c|c|}
\hline Subsidy & Un Rate & Income & Wage & Un Rate & Income & Wage \\
\hline \multicolumn{7}{|c|}{ High Skill: $p=1.4$} \\
\hline \multicolumn{4}{|c|}{ Case 1: $(\rho, T)=(0.2,0)$} & \multicolumn{3}{|c|}{ Case 2: $(\rho, T)=(0.34,0.78)$} \\
\hline $100 s$ & $u$ & $\Delta y / y$ & $\Delta \bar{w} / \bar{w}$ & $u$ & $\Delta y / y$ & $\Delta \bar{w} / \bar{w}$ \\
\hline 0 & 5.4 & 0.0 & 0.0 & 4.5 & 0.0 & 0.0 \\
\hline 4 & 5.1 & 0.0 & 3.2 & 4.3 & 0.0 & 3.2 \\
\hline 8 & 5.0 & 0.1 & 6.4 & 4.1 & 0.0 & 6.5 \\
\hline 12 & 4.8 & 0.1 & 9.6 & 3.9 & 0.0 & 9.7 \\
\hline 16 & 4.7 & 0.1 & 12.9 & 3.8 & 0.0 & 13.1 \\
\hline 20 & 4.5 & 0.1 & 16.1 & 3.6 & 0.0 & 16.2 \\
\hline \multicolumn{7}{|c|}{ Low Skill: $p=0.75$} \\
\hline \multicolumn{4}{|c|}{ Case 1: $(\rho, T)=(0.2,0)$} & \multicolumn{3}{|c|}{ Case 2: $(\rho, T)=(0.34,0.78)$} \\
\hline $100 s$ & $u$ & $\Delta y / y$ & $\Delta \bar{w} / \bar{w}$ & $u$ & $\Delta y / y$ & $\Delta \bar{w} / \bar{w}$ \\
\hline 0 & 9.0 & 0.0 & 0.0 & 16.2 & 0.0 & 0.0 \\
\hline 4 & 8.4 & 0.2 & 3.2 & 12.8 & 1.6 & 3.1 \\
\hline 8 & 7.9 & 0.3 & 6.3 & 10.8 & 2.4 & 6.2 \\
\hline 12 & 7.4 & 0.4 & 9.5 & 9.4 & 2.9 & 9.4 \\
\hline 16 & 7.0 & 0.5 & 12.7 & 8.4 & 3.2 & 12.6 \\
\hline 20 & 6.7 & 0.5 & 15.0 & 7.6 & 3.4 & 15.8 \\
\hline
\end{tabular}

In conclusion, an employment subsidy financed with a non-distortionary consumption tax has large positive effects on both the employment level and the wage earned. This conclusion is particularly true of low-skill workers in a regime of high unemployment compensation and employment protection. Furthermore, the subsidy offsets efficiency distortions induced by the payroll tax used to finance social security programs, by unemployment compensation, and by employment protection policy.

\subsection{Marginal Effects of a Hiring subsidy}

In this section, the simulated effects of a job creation subsidy are reported. A hiring subsidy is a payment that can be either a direct transfer to the employer or a tax rebate made to offset job creation costs. As $p H$ is the subsidy per worker hired and the gross hiring rate is the product of the unemployment hazard and the unemployment rate, a 
comparable measure is the total hiring subsidy flow divided by the total wage bill, i.e.,

$$
s=\frac{p H \theta q(\theta) u}{\bar{w}(1-u)}
$$

This measure is expressed in the same units as a wage subsidy and an employment subsidy normalized by wage.

The unemployment effects of a hiring subsidy for both policy cases and both worker skill groups are reported in Table 5. As reflected in equation (33), the gross subsidy flow is expressed as a percentage of the total wage bill for comparison with the results for an employment subsidy reported in Table 4 . Like the former table, wage and income effects are stated as percentage changes relative to their initial values, also to facilitate comparison.

The effect of the hiring subsidy on unemployment is positive in three of the four cases but negative for 'low skill' workers in policy scenario case 2. Recall, the qualitative effect of a hiring subsidy is theoretically ambiguous for the following reason. By making the cost of job creation less expensive, job creation is stimulated. However, a tighter market induces more job destruction as well because the opportunity cost of a match rises with $\theta$. Unemployment increases when the latter positive effect on unemployment incidence exceeds the former negative effect on unemployment duration. 
Table 5: Effects of a Hiring Subsidy

\begin{tabular}{|c|c|c|c|c|c|c|}
\hline$\overline{\text { Subsidy }}$ & Un Rate & Income & Wage & Un Rate & Income & Wage \\
\hline \multicolumn{7}{|c|}{ High Skill: $p=1.4$} \\
\hline \multicolumn{4}{|c|}{ Case 1: $(\rho, T)=(0.2,0)$} & \multicolumn{3}{|c|}{ Case $2:(\rho, T)=(0.34,0.78)$} \\
\hline$s$ & $u$ & $\Delta y / y$ & $\Delta \bar{w} / \bar{w}$ & $u$ & $\Delta y / y$ & $\Delta \bar{w} / \bar{w}$ \\
\hline 0 & 5.3 & 0.0 & 0.0 & 4.5 & 0.0 & 0.0 \\
\hline 4 & 6.2 & -0.4 & 5.1 & 6.2 & 0.8 & 6.0 \\
\hline 8 & 7.0 & -1.5 & 11.1 & 7.7 & -0.1 & 13.8 \\
\hline 12 & 7.7 & -3.4 & 17.9 & 8.8 & -2.1 & 23.3 \\
\hline 16 & 8.3 & -6.1 & 25.4 & 9.8 & -5.9 & 34.4 \\
\hline 20 & 8.9 & -9.5 & 33.8 & 10.5 & -11.2 & 47.3 \\
\hline \multicolumn{7}{|c|}{ Low Skill: $p=0.75$} \\
\hline \multicolumn{4}{|c|}{ Case 1: $(\rho, T)=(0.2,0)$} & \multicolumn{3}{|c|}{ Case $2:(\rho, T)=(0.34,0.78)$} \\
\hline $100 s$ & $u$ & $\Delta y / y$ & $\Delta \bar{w} / \bar{w}$ & $u$ & $\Delta y / y$ & $\Delta \bar{w} / \bar{w}$ \\
\hline 0 & 9.0 & 0.0 & 0.0 & 16.2 & 0.0 & 0.0 \\
\hline 4 & 9.6 & -0.3 & 4.6 & 15.0 & 1.7 & 4.6 \\
\hline 8 & 10.2 & -1.2 & 9.9 & 14.8 & 2.1 & 10.3 \\
\hline 12 & 10.6 & -2.7 & 15.8 & 14.5 & 1.3 & 17.0 \\
\hline 16 & 11.0 & -4.8 & 22.3 & 14.5 & -0.0 & 24.7 \\
\hline 20 & 11.3 & -7.4 & 29.4 & 14.5 & -3.1 & 33.5 \\
\hline
\end{tabular}

When unemployment compensation is low and there is no employment protection policy, the 'US' policy case 1, unemployment increases with the hiring subsidy for both high and low skill workers. However the reverse is true for low skill workers in the 'EU' policy case 2 characterized by high unemployment compensation and stringent employment protection. Furthermore, the subsidy decreases aggregate income by a substantial amount in case 1 for workers of both skill levels but can generate increases in case 2. The reason for this difference would seem to be the implicit firing cost of employment protection present in case 2 . The hiring subsidy offsets the negative effect of the firing cost on job creation and on aggregate income. That wages are bid up by a hiring subsidy in all cases is confirmed. Indeed, the wage is much more responsive to a hiring subsidy than to an employment subsidy increase of comparable size.

The lessons learned from this computational experiment are also clear. A hiring subsidy can decrease both employment and efficiency essentially by encouraging too much replacement of old jobs by new through creative destruction. Indeed, a hiring subsidy is welfare improving only to the extent that it offsets the negative effects of 
firing costs on job creation, as the earlier first best analysis indicated.

\subsection{A Self Financing Employment Subsidy and Wage Tax}

As a non-distortionary consumption or lump sum tax is not a practical possibility in fact, the results reported above overstate the net effects of employment and hiring subsidies by an amount equal to the dead weight loss of some alternative form of taxation. Furthermore, the only alternative in this environment, an income tax, is equivalent to a wage tax if employers can fully expense recruiting and training costs, as is the case under the US tax code. Hence, any employment subsidy must ultimately be financed by an offsetting increase in tax on labor earnings.

Because the distortion caused by a dollar collected from a wage tax is less than the offsetting effect of using that dollar to subsidize employment on the same worker, a fact noted above, employment, wage, and welfare improvements can be achieved in principle by increasing the wage tax and using the proceeds to subsidize employment even if there were only one worker type. However, the computed consequences of this policy (not reported here) are quite small, as one might expect, over a reasonable range of the subsidy and associated required tax.

Suppose instead one were to levy a surtax on high-skill workers and use the proceeds to target an employment subsidy to low-skill workers. To the extent that our previous results show that the impacts of the policy parameters are much larger for low-skill workers, this form of cross subsidization is likely to increase both the wage and the employment of low wage workers significantly with only a small negative effect on the wage and employment of high wage workers.

The results of a computational experiment along these lines are reported in Table 6. These numbers are obtained by calculating the market equilibrium for 'low' and 'high' skill workers simultaneously when the two markets are interconnected by a government budget constraint. As the wage surtax above and beyond the baseline payroll tax, $t-\tau$, levied on the 'high-skill' workers must cover the cost of a 'low-skill' employment subsidy $-a=s \bar{w}_{1}$, the constraint can be written as

$$
(t-\tau) \bar{w}_{2}\left(1-u_{2}\right) \ell_{2}=s \bar{w}_{1}\left(1-u_{1}\right) \ell_{1}
$$

where $\left(1-u_{i}\right) \ell_{i}$ is the equilibrium level of employment, $\ell_{i}$ is the fraction in the labor force, and $\bar{w}_{i}$ is the average wage of workers in skill group $i$ respectively given that $i=1(2)$ denotes the low (high) skill type. Reflecting the fact that about half of the US labor force have more than a high school education in the 90s, the computations in Table 6 reflect the assumption that $\ell_{1}=\ell_{2}=0.5$. 
Table 6: Effects of a 'Low-skill' Subsidy and 'High-skill' Surtax

\begin{tabular}{|c|c|c|c|c|c|c|}
\hline \multicolumn{4}{|c|}{ Policy Case 1: $(\rho, T)=(0.2,0)$} & & & \\
\hline $100 s$ & $u_{1}$ & $\Delta \bar{w}_{1} / \bar{w}_{1}$ & $u_{2}$ & $\Delta \bar{w}_{2} / \bar{w}_{2}$ & $\Delta y / y$ & $100(t-\tau)$ \\
\hline 0 & 9.0 & 0.0 & 5.3 & 0.0 & 0.0 & 0.0 \\
\hline 4 & 8.4 & 3.2 & 5.4 & -1.7 & 0.1 & 2.1 \\
\hline 8 & 7.9 & 6.3 & 5.4 & -3.5 & 0.1 & 4.4 \\
\hline 12 & 7.4 & 9.5 & 5.5 & -5.2 & 0.1 & 6.7 \\
\hline 16 & 7.0 & 12.7 & 5.5 & -7.0 & 0.1 & 9.2 \\
\hline 20 & 6.7 & 15.9 & 5.6 & -8.8 & 0.1 & 11.8 \\
\hline \multicolumn{7}{|c|}{ Policy Case 2: $(\rho, T)=(0.34,0.78)$} \\
\hline $100 s$ & $u_{1}$ & $\Delta \bar{w}_{1} / \bar{w}_{1}$ & $u_{2}$ & $\Delta \bar{w}_{2} / \bar{w}_{2}$ & $\Delta y / y$ & $100(t-\tau)$ \\
\hline 0 & 16.2 & .0 & 4.5 & 0.0 & 0. & 0.0 \\
\hline 4 & 12.8 & 3.1 & 4.6 & -1.6 & 0.5 & 2.0 \\
\hline 8 & 10.8 & 6.2 & 4.6 & -3.3 & 0.8 & 4.2 \\
\hline 12 & 9.4 & 9.4 & 4.7 & -5.1 & 1.0 & 6.6 \\
\hline 16 & 8.4 & 12.6 & 4.8 & -6.9 & 1.1 & 9.0 \\
\hline 20 & 7.6 & 15.8 & 4.9 & -8.7 & 1.1 & 11.6 \\
\hline
\end{tabular}

The results reported in Table 6 are quite encouraging. Over the rather reasonable low-skill employment subsidy range equal to 0 to $20 \%$ of earnings, the low-skill unemployment rate falls by over 2 points under the 'US' style policy and by more than half, from 16 to less than 8 percent, in the 'European' policy regime with very little impact on the level of unemployment of the high-skill workers in either case. Although the surtax on high-skill worker earnings lowers the wage of high-skill workers, the low-skill wage increases by twice as much in percentage terms. Furthermore, the low-skill wage increases by between 77 and 80 cents on the dollar of employment subsidy over the range studied in both policy cases. Hence, the combined subsidy-tax policy promotes considerable wage equality. At the same time, the level of aggregate income increases in response to the subsidy, particularly when unemployment compensation is high and employment protection is stringent.

Note that the cross wage tax and employment subsidization policy studied in this section is a reallocation scheme similar to the "earned income" tax credit that is part of the US income tax code. Like the credit in combination with a progressive income tax, those who earn more pay a higher marginal tax rate while those with low earnings receive 
an employment contingent income supplement. Indeed, in the environment under study the two schemes are formally equivalent because an employment subsidy has the same effects as an employment contingent payment made to the worker and the incidence of a wage tax is independent of whether it is the employer or the worker who actually pays it.

\section{Conclusions and a Future Research Agenda}

In the paper, we derive the effects of wage, employment, and hiring subsidies on job creation, job destruction, employment, and wages implied by an extended version of the Mortensen-Pissarides (1994) model of labor market equilibrium. Qualitative analytical results show that wage and employment subsidies increase employment, especially of low skill workers, and also increase wages. A job creation or hiring subsidy reduces unemployment duration but increases incidence with an ambiguous effect on overall employment. A firing tax has the reverse effects and also has an indeterminate employment effect.

Because a pure consumption tax has no effect on resource allocation decisions in the environment modeled, a first best tax and subsidy configuration always exists even when an unemployment compensation scheme and an employment protection policy are in place and when search externalities are present. One configuration includes the case of no wage tax, an employment subsidy set to offset the distortions of unemployment compensation and employment protection on the job destruction decision, and a hiring subsidy that corrects any job creation distortion imposed by employment protection and search externalities.

Computational experiments confirm that this ideal also determines the direction in which significant marginal improvements in both efficiency and equity can be made. However, simulation results also suggest that a hiring subsidy larger than that required to offset the effects of employment protection typically reduce employment and income by encouraging the replacement of old jobs with new too frequently. Finally, an employment subsidy targeted at low-skill workers but financed by a wage tax on high wage workers, a policy equivalent to an "earned income tax credit" in our framework, can induce significant increases in the employment and wage of low-skill workers with little increase in the unemployment rate of high wage workers.

There are many caveats to add concerning the limitations of the model used to draw these conclusions, and qualifications that identify needs for future research. Important among these is our assumption that the opportunity cost of employment as reflected in unemployment contingent income, or the value of leisure, $b$ in our notation, is indepen- 
dent of worker skill. This assumption is critical to the theoretical and computational outcomes reviewed above. To a first approximation, the quantitative importance of outcomes is proportional to the ratio of productivity to $b$. Empirical testing of this condition is, therefore, an important topic for future research.

Other research topics are suggested by the need to consider alternative specifications to those used here. For example, much has been made of worker "hold-up" possibilities that arise because match specific investments made by employers in hiring, training, and equipping a worker more generally are irreversible ex post. In this environment, workers have an incentive to renege on any initial agreement to share these costs through a lower wage. One parsimonious way to capture the effects of this time consistency problem is to assume that the initial wage is determined 'as if' the match specific investments were made prior to the initial wage bargaining game. The result would be an initial wage equal to the continuing wage at the initial value of the match specific component of productivity, i.e., $w_{0}=w(1)$ in the notation of the paper. As the employer incentives to create job vacancies are lower under this "insider-wage" contract, a hiring subsidy might be expected to perform somewhat better than under the investment sharing contract assumed in the paper. The effects given alternative methods of wage determination, particularly those associated with the 'efficiency wage' hypothesis, might also be studied.

In their analysis of wage subsidies using a similar model to ours, Davidson and Woodbury (1995) allow for endogenous worker search intensity. This generalization adds nothing to this analysis from a purely theoretical point of view but does introduce a new channel of influence for policy, skill, and bargaining power. Suppose the matching function takes the form $m(v, e u)$ where here $e$ represents the search effort of the typical unemployed worker. Given the assumption that effort reduces net value of leisure, say it is equal to $b\left(1-\frac{e^{1 / \gamma}}{\gamma}\right)$ where $\gamma \in(0,1)$, then one can show that optimal effort is a function of the market tightness. Formally,

$$
\begin{aligned}
b e^{\frac{1}{\gamma}-1} & =\frac{m(v, e u)}{e u}\left(W_{0}-U\right)=\frac{m(v, e u)}{e u} \frac{\beta\left(J_{0}-C+H\right)}{(1+t)(1-\beta)} \\
& =\left(\frac{v}{e u}\right) \frac{\beta p c}{(1+t)(1-\beta)}
\end{aligned}
$$

where the first equality is the first order condition for an individual's optimal choice of effort, the second is an implication of the bargaining outcome rule and the third equality is implied by the free entry condition. As a result, one can simply substitute appropriately to derive the reduced form matching function

$$
M(v, u)=m\left(v,\left(\frac{\beta p c(v / u)}{b(1+t)(1-\beta)}\right)^{\gamma} u\right) .
$$


Given $m$ concave and linearly homogenous, so is $M$, so the basic theory applies.

However, now the wage tax, skill productivity parameter and the "market power" parameter have added direct effects on the matching process given market tightness $\theta=v / u$ and indirect effects on the job creation and job destruction conditions. The reduced form vacancy hazard is now

$$
q(\theta)=\frac{M(v, u)}{v}=m\left(1,\left(\frac{\beta p c}{b(1+t)(1-\beta)}\right)^{\gamma} \theta^{\gamma-1}\right) .
$$

Otherwise, the job creation condition (23) holds as stated. Substituting $b\left(1-\gamma e^{1 / \gamma}\right)$ for unemployment contingent income $b$ on the right side of (22), we obtain the following modified opportunity cost of employment

$$
\frac{a+(1+t)\left(b\left(1-\gamma e^{1 / \gamma}\right)+\rho \bar{w}\right)}{p}+\frac{\beta(1-\gamma)}{1-\beta} c \theta-r T
$$

The principal qualitative changes are reductions in the sensitivity of the vacancy hazard and the opportunity cost of a match to the vacancy-unemployment ratio. In addition, a wage tax now discourages search effort which in turn reduces the equilibrium employer incentive to create jobs, given the complementarity of vacancies and search effort in the matching function.

The Davidson and Woodbury specification also differs from ours by assuming that the total number of jobs available is fixed rather than endogenously determined by a free entry condition. Not surprisingly, they conclude that a targeted subsidy will have a large displacement effect. Still, their result illustrates that our specification assumes a large part of the crowding-out problem away. One way to introduce a middle ground would be to assume that worker productivity depends on employment levels. For example, let $p_{i}=f_{i}\left(n_{1}, n_{2}\right)$ where $n_{i}=\left(1-u_{i}\right) \ell_{i}$ represents the employment level of skill group $i$ and where $f_{i}($.$) , the marginal product of skill i$ workers, allows for diminishing returns and substitution between the two worker types.

\section{References}

[1] Binmore, K.G., A. Rubinstein, and A. Wolinsky (1986). "The Nash Bargaining Solution in Economic Modelling," Rand Journal of Economics 17: 176-188.

[2] Burda, M.C. (1992). "A Note on Firing Costs and Severance Benefits in Equilibrium Unemployment," Scandinavian Journal of Economics 39, 479-89. 
[3] Davidson, K., and S.A. Woodbury (1995). "Wage Subsidies for Dislocated Workers," Upjohn Institute Staff Working Paper 95-31.

[4] Davis, S.J., J. Haltiwanger, and S. Schuh (1996). Job Creation and Destruction. Cambridge, MA: MIT Press.

[5] Diamond, P.A. (1981). "Mobility Costs, Frictional Unemployment, and Efficiency," Journal of Political Economy 89, 798-812.

[6] Diamond, P. A. (1982a). "Aggregate Demand Management in Search Equilibrium," Journal of Political Economy 90, 881-894.

[7] Diamond, P.A. (1982b). "Wage Determination and Efficiency in Search Equilibrium," Review of Economic Studies 49, 217-227.

[8] Friedman, M. (1968). "The Role of Monetary Policy," American Economic Review $58,1-17$.

[9] Hosios, A. J. (1990). "On the Efficiency of Matching and Related Models of Search and Unemployment," Review of Economic Studies 57, 279-298.

[10] Lazear, E. (1990). "Job Security Provisions and Employment," Quarterly Journal of Economics 105, 699-726.

[11] MacLeod, W.B., and J. Malcomson (1993). "Investments, Holdup, and the Form of Market Contracts," American Economic Review 83, 811-837.

[12] Millard, S.P., and D.T. Mortensen (1996). "The unemployment and welfare effects of labour market policy: A Comparison of the US and UK" in D. Snower and G. de la Dehesa (eds.), Unemployment Policy: How Should Governments Respond to Unemployment? Oxford: Oxford University Press.

[13] Mortensen, D.T. (1982). "The Matching Process as a Noncooperative/Bargaining Game." In J.J. McCall (ed.), The Economics of Information and Uncertainty, 233254. Chicago: University of Chicago Press.

[14] Mortensen, D.T. (1994). "Reducing Supply Side Disincentives to Job Creation" in Reducing Unemployment: Current Issues and Policy Options. Kansas City: Federal Research Bank of Kansas City.

[15] Mortensen, D.T. (1978). "Specific Capital and Labor Turnover," The Bell Journal of Economics 9(2), 572-586. 
[16] Mortensen, D.T., and C.A. Pissarides (1994). "Job Creation and Job Destruction in the Theory of Unemployment," Review of Economic Studies (1994) 61, 397-415.

[17] Organisation for Economic Cooperation and Development, OECD, (1994), Jobs Study. Paris: OECD.

[18] Petrongolo, B. and C. A. Pissarides (2001). "Looking into the Black Box: A Survey of the Matching Function." Journal of Economic Literature June.

[19] Phelps, E.S., et.al (1970). Microeconomic Foundations of Employment and Inflation Theory. New York: W.W. Norton and Co., Inc.

[20] Phelps, E.S. (1968). "Money-wage Dynamics and Labor Market Equilibrium," Journal of Political Economy 76, 254-81.

[21] Phelps, E. S. (1997). Rewarding Work. Cambridge, MA: Harvard University Press.

[22] Pissarides, C. A. (1986). "Unemployment and Vacancies in Britain," Economic Policy 3, 499-559.

[23] Pissarides, C.A. (1990). Equilibrium Unemployment Theory. Oxford: Basil Blackwell.

[24] Pissarides, C.A. (1985). "Short-Run Equilibrium Dynamics of Unemployment, Vacancies and Real Wages", American Economic Review 75, 676-90.

[25] Rubinstein, A., and A. Wolinsky (1985), "Equilibrium in a Market with Sequential Bargaining", Econometrica 53, 1133-1150.

[26] Stigler, G. J. (1961). "The Economics of Information," Journal of Political Economy $69,213-225$.

[27] Wolinsky, A. (1987). "Matching, Search, and Bargaining," Journal of Economic Theory. 


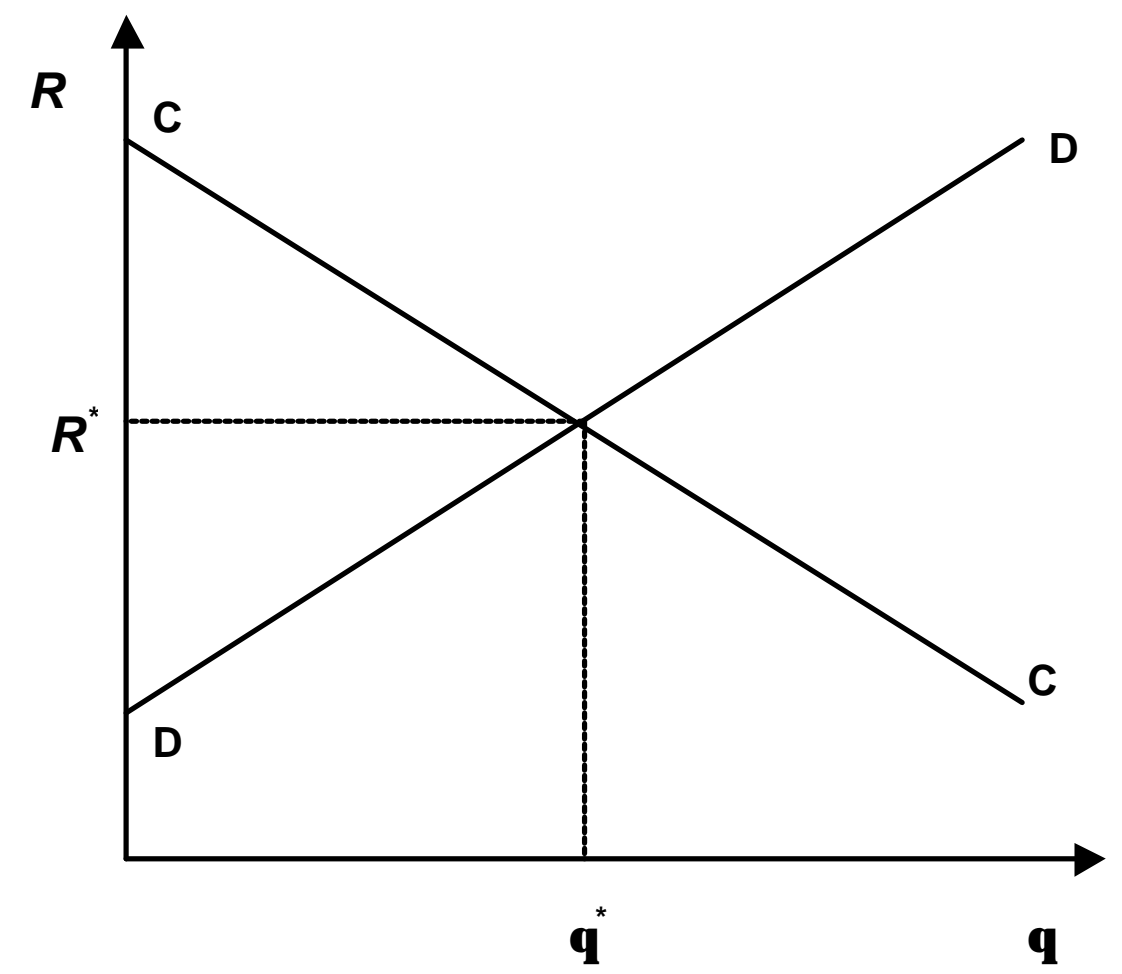

Figure 1: Search Equilibrium 


\section{CENTRE FOR ECONOMIC PERFORMANCE \\ Recent Discussion Papers}

$518 \quad$ D. Clark

R. Fahr

517 J. Blanden
A. Goodman
P. Gregg
S. Machin

516 A. Chevalier

T. K. Viitanen

515 A. Bryson

R. Gomez

M. Gunderson

N. Meltz

514 A. Manning

513 H. Steedman

512 R. Gomez

M. Gunderson

N. Meltz

511 G. Duranton

D. Puga

510 P.-P. Combes

G. Duranton

509 R. Griffith

S. Redding

J. Van Reenen

508 H. G. Overman

S. Redding

A. J. Venables

507 A. J. Venables
The Promise of Workplace Training for Non-College

Bound Youth: Theory and Evidence from Germany

Change in Intergenerational Mobility in Britain
The Long-Run Labour Market Consequences of Teenage Motherhood in Britain

Youth Adult Differences in the Demand for Unionisation: Are American, British and Canadian Workers That Different?

Monopsony and the Efficiency of Labor Market Interventions

Benchmarking Apprenticeship: UK and Continental Europe Compared

From 'Playstations' to 'Workstations': Youth Preferences for Unionisation

From Sectoral to Functional Urban Specialisation

Labor Pooling, Labour Poaching, and Spatial Clustering

Measuring the Cost Effectiveness of an R\&D Tax Credit for the UK

The Economic Geography of Trade, Production and Income: A Survey of Empirics

Geography and International Inequalities: the Impact of New Technologies 
Fixed-Term Contracts and the Duration Distribution of Unemployment

504 A. Charlwood

503 D. Marsden

S. French

K. Kubo

502 S. Nickell

L. Nunziata

W. Ochel

G. Quintini

$501 \quad$ S. Redding

M. Vera-Martin

$500 \quad$ Edited by

D. Marsden and

H. Stephenson

499

498 A. Charlwood

497
M. Keil
D. Robertson
J. Symons

496 A. Di Liberto

J. Symons

$495 \quad$ S. Redding

A. J. Venables

494 A. Bryson
Influences on Trade Union Organising Effectiveness in Great Britain

Does Performance Pay De-Motivate, and Does It Matter?

The Beveridge Curve, Unemployment and Wages in the

OECD from the 1960s to the 1990s

Factor Endowments and Production in European Regions

Labour Law and Social Insurance in the New Economy: A

Debate on the Supiot Report

A Generalised Model of Monopsony

Why Do Non-Union Employees Want to Unionise?

Evidence from Britain

Minimum Wages and Employment

Education and Italian Regional Development

Economic Geography and International Inequality

Union Effects on Managerial and Employee Perceptions of Employee Relations in Britain

To order a discussion paper, please contact the Publications Unit Tel 02079557673 Fax 02079557595 Email info@cep.lse.ac.uk Web site http://cep.lse.ac.uk 